\title{
A CIDADE DE MOSSORÓ, RIO GRANDE DO NORTE: processo de formação e produção do espaço urbano
}

\author{
Camila Dutra dos Santos \\ Mestrado Acadêmico em Geografia (MAG, Universidade Estadual do Ceará \\ Av. Paranjana, 1700 - Campus do Itaperi - CEP: 60.020-180 Fortaleza/CE, Brasil \\ Tel.: (55 85) 3101.9611 - camilageo@hotmail.com
}

\begin{abstract}
RESUMO
Os sucessivos reajustamentos sociais e econômicos na região Nordeste serviram para consolidar algumas formas e funções urbanas, reorganizando o espaço das cidades sertanejas. Este artigo objetiva tecer algumas considerações a respeito do processo de produção do espaço urbano de Mossoró, analisando também a sua atual dinâmica urbana, cuja reprodução, guardando as devidas proporções, não foge da complexidade presente na rede urbana nordestina. A circulação de novos agentes e de mercadorias associadas às três principais atividades econômicas de Mossoró - sal, petróleo e fruticultura - resultou em maior demanda de consumo, refletindo-se, conseqüentemente, na urbanização e na economia dessa cidade. A cidade de Mossoró vem se destacando como centro urbano polarizador, com característica marcante de uma diversificação tanto de serviços, quanto de produção de insumos, concentrando também maior fluxo monetário. Compreender tal complexidade demanda investigações que levem em conta o fato de que, a cidade é uma expressão material do modo de produção onde está situada e que, ao mesmo tempo, cria continuamente condições para sua manutenção e reprodução.
\end{abstract}

Palavras-chave: Nordeste, Mossoró, Cidade, Espaço Urbano.

\begin{abstract}
Successive social and economic readjustments in the Brazilian Northeast Region has contributed to consolidate some urban forms and functions, reorganizing the space of the Hinterland cities. This article aims to make a few observations about the space production's process in the city of Mossoró, also considering its current urban dynamics that don't escape the complexity of the Northeast's urban network. The movement of new agents and merchandises associated with the three main economic activities of Mossoró - salt, oil and fruit production - has resulted greater consumer's demand, reflecting, therefore, in the city's urbanization and economy. The city of Mossoró has been excel as a polarizing urban center, with a great diversification in the services and the production inputs, also concentrating great money flow. Understanding that complexity demands investigations that considers the fact that cities are material expression of the mean of production in the context where it is located and at the same time, continuously creates conditions for their maintenance and reproduction.
\end{abstract}

Key words:Brazilian Northeast, Mossoró, City, Urban Space.

\section{RÉSUMÉ}

Successives ajustements économiques et sociaux dans le Nordeste a servi à consolider des formes et fonctions urbaines, en réorganisant l'espace des villes dans l'arrière-pays. Cet article vise à faire quelques observations sur le procés d'occupation et de la production de l'espace urbain de Mossoró, en analysant aussi sa dynamique urbaine actuelle, dont sa reproduction, en conservant les proportions, ne fuit pas à la complexité actuelle dans le réseau urbaine du Nordeste. Le mouvement des nouveaux agents et de marchandises associés avec les trois principales activités économiques dans le Mossoró - sel, petróle et la production de fruits - a résulté aussi en majeur demande pour la consommation, ce qui reflète, par conséquent, en l'urbanisation et en l'économie de cette ville. La ville de Mossoró vient en se détachant comme centre polariseur, avec une caractéristique de la diversification des services, autant de la production de intrants, aussi en concentrant plus de les flux monétaires. La compréhension de cette complexité demande des enquêtes qui prennent en compte le fait qui, la ville est une expression du mode de production où il se trouve et, en même temps, ne cesse de créer les conditions pour leur manutention et sa reproduction.

Mots-clés: Nordeste, Mossoró, Ville, Espace Urbain.

\section{INTRODUÇÃO}

O processo de reestruturação produtiva ao qual estamos inseridos é ainda ponto de indefinições e inesgotáveis investigações. Ponto de comum acordo, entre os autores que o estudam, é o reconhecimento da certeza de que estamos envolvidos num novo período histórico de continua 
e intensa reestruturação. O movimento incessante é a marca do atual período histórico, assim as reestruturações se apresentam como a expressão fenomênica desse período, materializada em várias possibilidades: reestruturação da política, da técnica, da cultura, em que todas têm como base material a reestruturação do espaço, que é meio e produto desse processo (MOREIRA, 1982).

Enquanto para alguns autores, estamos inseridos em um regime de acumulação inteiramente novo (HARVEY, 2003), outros acreditam que tal processo não se generaliza em todos os circuitos da economia, que se trata de "uma mescla complexa e irresoluta de continuidade e mudança" (SOJA, 1993, p.194). Em nossa opinião, estas duas formas de ver as recentes transformações da sociedade estão corretas, mas devem ser complementares. O regime de acumulação do capital, no qual estamos inseridos, é inteiramente novo sim, mas, como todo regime de acumulação, as formas históricas mais avançadas não eliminam as formas históricas anteriores. Isto porque, o novo nunca vai acabar com o velho, eles sempre vão coexistir.

Assim, convivem dentro de um mesmo complexo espacial formas novas e antigas e complexos inteiramente novos com complexos inteiramente arcaicos. O desafio do pesquisador é ver, então, como o novo e o velho se articulam no processo de produção e reprodução das forças produtivas. Soja (Ibid., p. 198) fala de um desenvolvimento geograficamente desigual como sendo "uma parte essencial da espacialidade capitalista, de sua matriz espacial e sua topologia características". Este tipo de desenvolvimento aparece como uma importante fonte de manutenção dos lucros e implica na produção de diferenciações espaciais.

Neste movimento incessante de reestruturações, o espaço se torna, com muito mais ênfase nos dias atuais, lócus da produção e das trocas globalizadas, recebendo capital e ordens, na maioria das vezes, de lugares muito distantes daqueles onde verdadeiramente se realiza a produção. É o espaço que, em resposta às transformações gerais da sociedade, toma a forma do que Santos (2005, p.38) chamou de meio técnico-científico-informacional, "marcado pela presença da ciência e da técnica nos processos de remodelação do território essenciais às produções hegemônicas, que necessitam desse novo meio geográfico para a sua realização".

São as mudanças na composição técnica do território como, os investimentos em infra-estruturas, ampliação e crescimento da rede de transportes e comunicação, expansão de atividades modernas e dinâmicas que vão possibilitar uma generalização do meio técnico-científico-informacional, não necessariamente de forma contínua, mas muitas das vezes em manchas e pontos ou apenas enquanto tendência ou possibilidade. A verdade é que, a globalização não chega para todos da mesma forma e no mesmo tempo e espaço. Os lugares vão sendo valorizados e desvalorizados conforme a política territorial de expansão do capital.

Se uma série de vetores, por muito tempo, determinou a concentração de empresas na Região Concentrada ${ }^{1}$ (SANTOS; SILVEIRA, 2003), vem ocorrendo nas últimas décadas uma difusão dessa especialização para o Nordeste, a partir da constituição de uma densidade técnica e normativa fomentada por atores econômicos com a forte intervenção do Estado. É exatamente aqui que entram os espaços de reserva (SANTOS, 1993 apud ELIAS, 2006), antigas áreas do território brasileiro, que antes não despertavam interesses para investimentos do capital, e que hoje estão sendo incorporadas fortemente a esta lógica.

A cidade de Mossoró, nosso objeto de análise, por exemplo, faz parte dos antigos espaços de reserva do capital no Nordeste brasileiro, e foi incorporado à acumulação ampliada do capital, por conter, principalmente a partir da década de 1980, condições favoráveis a essa expansão capitalista, como o investimento maciço de capital público e privado na tecnificação do seu território.

\section{DIVISÃO TERRITORIAL DO TRABALHO E PRODUÇÃO DO ESPAÇO NORDESTINO}

A região Nordeste, por seu clima tropical semi-árido, que é gerador de prolongados períodos de chuvas irregulares, foi, por muito tempo, considerada como "região problema", pelo estigma das secas. Esse discurso convincente da seca - culpando o céu que não deixa chover, sempre esteve 
atrelado a uma imagem de sofrimento, desde muito tempo apropriada para encobrir os reais motivos dos problemas sociais no semi-árido e as ligações desses com as relações de produção. Castro (1992, p. 60), ao tratar de um Nordeste produzido por suas elites político-econômicas, disse que "é significativa a ambivalência da história política da região, cuja oligarquia, enquanto se apropriava da imagem da pobreza, participava ativamente do bloco do poder do Estado".

Com base neste discurso, até o final dos anos 1940 predomina um período de ações assistencialistas por conta do Estado. São disponibilizados recursos técnicos e financeiros com vistas a minorar os efeitos de um processo que é natural: a seca. Para isto foram construídos pela Inspetoria Federal de Obras Contra as Secas (IFOCS) ${ }^{2}$ : poços, açudes, canais, todos dentro do discurso da "proteção hídrica".

No fim dos anos 1950, o discurso do Estado e das elites econômicas do Nordeste assume outra dimensão. A Superintendência de Desenvolvimento do Nordeste (SUDENE) é criada com a justificativa de estimular a industrialização como forma de superar as dificuldades econômicas dessa região. No entanto, a história nos mostra que o que verdadeiramente estava por trás de tal discurso, nada mais era do que, um planejamento estratégico de expansão capitalista no país, como bem enfatiza Oliveira (1981, p. 26):

Por outro lado, o projeto inicial da SUDENE, apesar de sua flamante retórica, provavelmente esgotarse-ia num esforço de coordenação - de duvidosa eficácia, segunda a experiência dessa categoria de planejamento - se não lhe tivesse atribuído a tarefa de ser 'correia transportadora' da hegemonia burguesa do Centro-Sul para o Nordeste, pela via de incentivos fiscais do sistema 34/18.

Essa forte alteração na orientação dos fluxos econômicos fez migrar o capital produtivo do Centro-Sul para o Nordeste, materializando-se na crescente instalação de grandes grupos empresariais nesta região. Com o apoio dos incentivos estatais e isenção de impostos, essas unidades produtivas diversificaram sua produção, ampliaram e modernizaram suas empresas ou abriram outras unidades produtivas. O Estado aparece, aqui, portanto, como um componente estratégico de acumulação capitalista, como evidencia Araújo (1997, p.12):

É evidente que o Estado patrocinou fortemente o crescimento econômico das diversas regiões brasileiras. No Nordeste, porém, pode-se afirmar que sua presença foi fator fundamental para explicar a intensidade e os rumos do crescimento econômico ocorrido nas últimas décadas. Direta ou indiretamente, foi o setor público que puxou o crescimento das atividades econômicas que mais se expandiram na região nos anos 70 e 80 .

A partir das diretrizes impostas pela SUDENE, estabeleceu-se uma nova divisão territorial do trabalho que impôs ao Nordeste a função de produtor de matérias-primas para as regiões Sul e Sudeste. Os interesses do capitalismo internacional, que concentrou investimentos no Centro-Sul do país culminaram em uma nova indústria modernizada, enquanto a dinâmica econômica tradicional do Nordeste - que no caso do Sertão, esteve por muitos anos centrada nas atividades de beneficiamento do algodão - não encontrou mercado para sobreviver.

A política territorial das grandes empresas, que antes buscavam as benesses das localizações metropolitanas, sobretudo na região Sudeste, descentraliza suas indústrias e direcionam seus investimentos para outras porções do território brasileiro. Principalmente a partir da década 1980, os novos sistemas de objetos e sistemas de ações (SANTOS, 1996) permitiram que os grupos econômicos pudessem redefinir sua lógica de atuação e localização possibilitando maior mobilidade do processo produtivo, o que não implicou em descentralização econômica, pois os processos econômicos ligados às decisões, comandos e gestão permaneceram nas suas cidades de origem.

A estratégia dessa desconcentração espacial é a de recomposição dos lucros do capital e aumento da produtividade. Por isso que as empresas vêm se transferindo principalmente para 
lugares onde possam encontrar uma boa situação geográfica (SPOSITO, 2006), isto é, terras e mão-de-obra baratas, incentivos fiscais, isenção de impostos, mercados consumidores na "periferia" do sistema e outras benesses para o capital.

É ainda importante lembrar que o processo de desconcentração espacial trás consigo o germe de uma reconcentração seletiva, pois as unidades produtivas não vão para todos os lugares e nem para qualquer lugar. Conseqüência direta desse processo é o que podemos chamar de guerra dos lugares (SANTOS; SILVEIRA, 2003). É como se existisse um mercado global para venda de virtualidades, onde cada lugar compete para atrair o máximo de investimentos e vetores de modernização para sua fronteira a partir de vantagens competitivas que garantam uma maior rentabilidade aos atores hegemônicos. Aqui as demandas cumpridas pelas cidades acabam sendo majoritariamente reclamada pelas empresas. A cidade aparece aqui como uma expressão material da divisão social do trabalho, pois como já falava Sposito $(2001$, p. 30):

As transformações, que historicamente se deram, permitindo a estruturação do modo de produção capitalista constituem conseqüências contundentes do próprio processo de urbanização. A cidade nunca fora um espaço tão importante, e nem a urbanização um processo tão expressivo e extenso a nível mundial, como a partir do capitalismo.

A existência de atores econômicos hegemônicos sobre um dado território acaba por ser, ao mesmo tempo, resultado e causa de uma disputa por lugares mais "rentáveis", na verdade, estes constituem os espaços de eleição global para certos produtos. E enquanto um lugar pode valorizar-se em dado momento para o exercício de certo nível de capital, pode, por outro lado, tornar-se menos valioso para outros tipos de capitais e produtos. A isto se deve a afirmação de Santos e Silveira (2003, p.144), quando dizem que, "ao longo do tempo, cada lugar é alvo de sucessivas divisões do trabalho. Mas esse mesmo lugar, visto num corte temporal, isto é, num momento dado, acolhe simultaneamente várias divisões do trabalho".

A superposição de divisões territoriais do trabalho no Nordeste teve rebatimentos nas formas e funções urbanas das cidades nordestinas. No caso do Rio Grande do Norte, essas cidades foram produzidas em função da pecuária, e, posteriormente, da cultura do algodão para o mercado internacional, mas sua explicação de origem mesmo está ainda na primeira divisão territorial do trabalho do Nordeste quando a economia açucareira na Zona da Mata induziu o surgimento e a expansão da pecuária no Sertão. As cidades foram ganhando formas e funções conforme seu grau de aproximação do Sertão e do Litoral.

É importante destacar que a ocupação do sertão nordestino deu-se de forma tardia dentro do contexto da região Nordeste. As condições naturais não favoráveis e a hostilidade de alguns grupos indígenas adiaram, por tempo considerável, as tentativas de colonização das áreas sertanejas. A primeira e mais importante base de fixação do povoamento no Rio Grande do Norte foi a pecuária extensiva (e não a cana-de-açúcar) diferenciando-se da forma como ocorreu no litoral do Nordeste, porém, significativamente associada à produção açucareira, já que a pecuária também fornecia o couro para embalar as suas mercadorias.

As correntes migratórias vindas das regiões açucareiras de Pernambuco e Bahia atraídas pela ascensão da pecuária foram responsáveis pela ocupação de diversas áreas não só do Rio Grande do Norte como no Nordeste em geral. O gado era criado em fazendas instaladas próximas aos rios e comercializado em feiras das cidades de Olinda, Igaraçu, Goiana e Recife, bem como a própria carne-seca se tornou, posteriormente, artigo alimentício básico no período colonial.

Este ciclo econômico favoreceu o surgimento de vilas, que depois viraram cidades. Aquelas favorecidas pela localização junto ao cruzamento de estradas (muitas se originaram dos caminhos das boiadas) ou próximas a portos naturais, cresceram e se destacaram na rede de cidades nordestinas. Os portos de algumas dessas cidades serviram na época como centros de convergência da produção regional e distribuição comercial. Para Arroyo (2006, p. 81) “(...) é na encruzilhada da 
circulação, das redes, dos fluxos que as cidades crescem ou se estancam”.

Na segunda metade do século XIX, a produção algodoeira vem somar-se à pecuária formando o "binômio gado-algodão". Decorrente da crise da produção de algodão nos Estados Unidos, o algodão nordestino vira artigo de exportação e soergue a economia de muitas cidades sertanejas que haviam decaído com os anteriores períodos prolongados de seca. O surto algodoeiro induziu o surgimento de atividades industriais de beneficiamento do algodão, e as primeiras descaroçadeiras e prensas de algodão se constituíram na primeira unidade fabril das cidades sertanejas.

Os núcleos populacionais nordestinos foram evoluindo para condição de cidade à medida que iam encontrando aberturas para se tornarem centros de trocas de mercadorias. Alguns, antes de se tornarem centros de convergência da produção regional, foram alvos de atividades eminentemente administrativas, militares e religiosas.

Verificamos que algumas cidades nordestinas são herdeiras de uma tradição econômica surgida em períodos anteriores, mas cuja especialização se perfaz em décadas recentes. Cidades sertanejas como Campina Grande (PB), Mossoró (RN), Sobral (CE) e Caruaru (PE), em um primeiro momento se conformam em empório comercial, ou seja, como centros repassadores da produção do seu espaço regional e também como sede de fábricas, indústrias e prestação de serviços. De acordo com Felipe (1982), num segundo momento esse capital acumulado, através das atividades comerciais, passaria a comandar o desenvolvimento dessas cidades.

A urbanização, a partir dos anos 1950, chega junto com as novas transformações de ordem econômica, social e dos sistemas de transportes e comunicação. O fator crucial desta urbanização, agora mais acelerada e marcante, deve-se à ampliação da mobilidade da população através de intensas migrações. A falta de terra e a seca castigante empurram a população rural para as cidades na espera de uma vida melhor, que não chega.

Na década de 1960, sucedem-se também crises na agroindústria nordestina que redefine a economia de algumas cidades do Rio Grande do Norte. Nesse momento de redefinições, uma série de políticas e programas é dirigida especificamente para duas cidades do Rio Grande do Norte: Natal e Mossoró. Natal com mais vantagens e condições por ser o centro administrativo do estado e pela concentração de instituições militares e órgãos do Governo Federal, e Mossoró enquanto centro prestador de serviços, até certo ponto complementares aos de centros urbanos maiores como Natal e Fortaleza. Um dos mais importantes programas que contemplou estas duas cidades na década de 1970 foi o Programa de Cidades Médias, o qual resultou da iniciativa da Comissão Nacional de Regiões Metropolitanas e Política Urbana possuindo uma abrangência nacional, e tendo sido de muita importância para as cidades onde foi adotado. Segundo Rocha (2005, p. 184):

Para essas cidades, o Programa de Cidades de Porte Médio foi um marco, tendo em vista que, com os recursos desde, foi implementado o planejamento urbano local, de modo que as cidades contempladas passaram a contar com vários equipamentos urbanos até então inexistentes, proporcionando melhores condições de vida às suas populações.

Segundo Felipe (op. cit.), as décadas de 1960 e 1970 prepararam o caminho para as dificuldades e os problemas sociais de Natal e de Mossoró que temos hoje. É nesse contexto que é reforçado estrategicamente a economia urbana de Mossoró em direção ao terciário. A partir de então, Mossoró assumiria, de forma mais enfática, a função no contexto regional de um centro prestador de serviços. Uma das conseqüências da centralização dos investimentos públicos foi o aumento da dependência política, econômica e de prestação de serviços por parte de muitos centros urbanos do Rio Grande do Norte em relação à Natal e Mossoró. 


\section{LÓGICAS, DINÂMICAS E TRANSFORMAÇÕES NA PRODUÇÃO DO ESPAÇO URBANO EM MOSSORÓ}

Mossoró se localiza político-administrativamente na mesorregião Oeste Potiguar e na microrregião de Mossoró, possuindo localização privilegiada principalmente por estar situada entre duas capitais - Natal (RN) e Fortaleza (CE), estando mais próxima de Fortaleza $(260 \mathrm{~km})$, o que influi na sua estreita relação com o estado cearense. Mossoró é a cidade de convergência de praticamente todas as vias que servem a sua microrregião. A rodovia BR-304, que passa por Mossoró, ligando Fortaleza a Natal, assume o papel de corredor de oferta de serviços e comércio, tanto para a atividade da fruticultura, como para a salineira e petrolífera (ROCHA, Op. cit.).

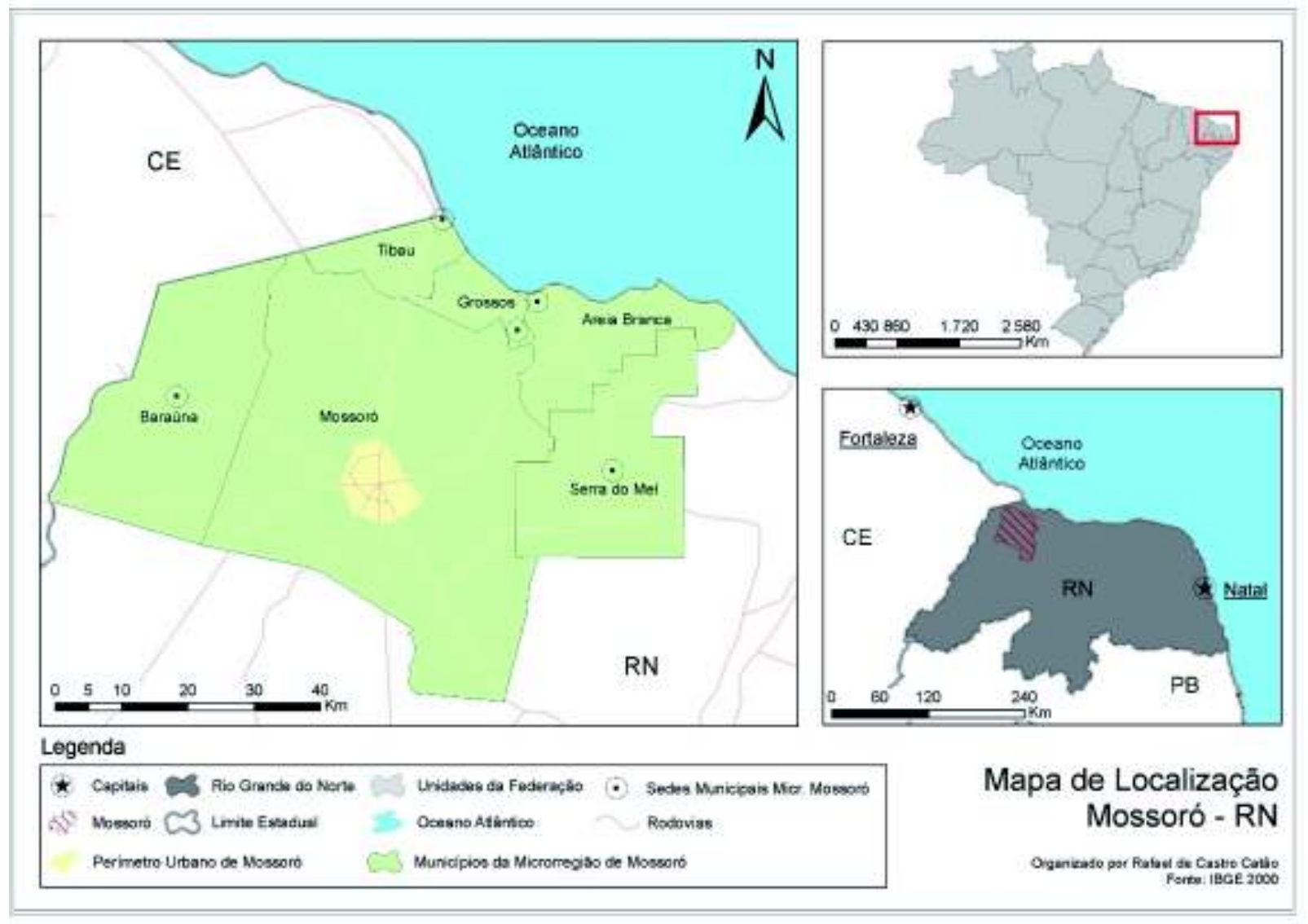

Figura 1 - Localização de Mossoró - RN

Sentado na área de transição entre a economia do litoral e a do sertão, Felipe (1988) vai dizer desse município que essa sua geografia conduziu a cidade a entrar mais facilmente nas novas divisões territoriais do trabalho. As formas e os processos, pelos quais ocorreu a ocupação e formação urbana de Mossoró, possibilitaram esta cidade ser hoje a segunda maior do Rio Grande do Norte e pólo da região oeste do estado.

Quando descreve as transformações na divisão territorial do trabalho no Rio Grande do Norte, Felipe $(1982,1988)$ mostra que o caráter polarizador de Mossoró não é recente. Esse autor apresenta os diferentes períodos pelos quais Mossoró passou em seu desenvolvimento econômico como: empório comercial, agroindústria, produção de sal artesanal e, mais recentemente, a produção mecanizada de sal, a exploração do petróleo e a fruticultura irrigada, momentos que convivem e se sobrepõem na história mossoroense.

Os primeiros arranjos no espaço de Mossoró aparecem em meados do século XIX com a chegada dos navios da Cia. Pernambucana de Navegação Costeira. Esta companhia, ao fazer escala regular no porto de Mossoró, motivou a chegada de novos comerciantes à cidade. No período de 
1860 a 1870 houve um surto de crescimento no número de casas, armazéns e de estabelecimentos comerciais, que gerou as bases para a formação do empório comercial em Mossoró. Esta cidade foi aos poucos se consolidando enquanto centro de comercialização de uma área que atingia, além dos municípios vizinhos, partes dos estados do Ceará e da Paraíba.

Mossoró, mesmo não estando encravado no litoral, contava com um porto que era o Porto de Mossoró ou Porto de Areia Branca, município que pertenceu a Mossoró até 1892, quando foi desmembrado. Do sertão vinham o algodão, a pecuária e as peles de animais; do litoral vinham o sal, a carne seca e o peixe. Mossoró tornava-se naquele momento o lugar de troca, pois recebia mercadorias de outras praças, do país e do exterior, e embarcava pelo seu porto a produção regional, que se destinava ao mercado nacional e internacional.

Quando o "empório comercial" se estagna, pela saída de capitais e empresas, esvaziamento gerado pelo retardamento da estrada de ferro, os capitais gerados pelo comércio em sua época áurea são adicionados aos capitais ligados às salinas e juntos trarão para Mossoró outra especialização, agora ligada ao extrativismo - algodão, oiticica, carnaúba. Em um período posterior aos anos 1920 é que se ampliam as agroindústrias de beneficiamento destes produtos. Ao capital gerado pelas agroindústrias é adicionado os rendimentos da extração do sal, que desde 1987 já havia sido sistematizada, mesmo com as salinas artesanais. Ainda conforme explica Felipe (op. cit., p.32):

O traçado urbano da cidade ainda guarda as heranças daquela época: as ruas largas, a densidade de edifícios no centro comercial, as residências ao longo da ferrovia, dividindo esse espaço com os armazéns de sal, as fábricas de algodão, óleo de oiticica e cera de carnaúba.

A falência da agroindústria nordestina atinge Mossoró no início da década de 1960. Os interesses do capitalismo internacional, que concentra investimentos no Centro-Sul do país dentro do quadro político da SUDENE, impõem uma nova indústria modernizada na qual a tradicional agroindústria não encontra mercado para sobreviver. Portanto, no início dos anos 1970, Mossoró apresenta um quadro crítico econômico por conta das dificuldades que as agroindústrias passavam com o fechamento dos algodoeiros e fábricas de óleos e, por outro lado, por conta do processo de mecanização da produção do sal que dispensou um grande número de trabalhadores e eliminou pequenas e médias salinas, as quais não conseguiram acompanhar a modernização.

Esse quadro de crises fez com que Mossoró procurasse novos caminhos para sobreviver como cidade e centro regional. É a partir de então que a característica de centro prestador de serviços emerge nesta cidade. A relação entre a produção e o terciário (e, por conseqüência, entre a urbanização) é historicamente expressiva na organização do espaço urbano mossoroense.

Como toda cidade, Mossoró está atravessada por circuitos espaciais de produção e círculos de cooperação (SANTOS, 1994, 1996; SANTOS, SILVEIRA, 2003). Dentro desses circuitos produtivos, chamou nossa atenção à extração de sal e petróleo e a produção de frutas tropicais tipo exportação, que vêm provocando significativos impactos na economia urbana de Mossoró. Para atrair e permitir a continuidade dessas novas dinâmicas econômicas, os agentes produtores dessa cidade vêm organizando-a em função, embora não exclusivamente, dessas três atividades econômicas, as quais, mesmo com suas diferenças, possuem uma marca em comum que é a de se apropriarem do espaço urbano mossoroense e organizá-lo em função dos interesses de seus atores hegemônicos.

A lógica territorial das empresas dos circuitos espaciais da produção analisados, promove em Mossoró uma vida de relações próprias às suas demandas produtivas. Essas empresas encontraram (e encontram) em Mossoró, uma condição de produção, uma cidade inserida no contexto do meio técnico-científico-informacional, o que propicia diferentes rentabilidades aos novos capitais. Segundo Rocha (2005, p.16): 
No caso específico de Mossoró, os processos sociais que formatam a cidade e dinamizam a sua sociedade são marcados por uma reestruturação econômica com reflexos em todo o território municipal, principalmente no espaço urbano, onde essas economias fazem a sua produção ou o processo de gestão, transformação e escoamento de seus produtos e serviços.

É perceptível em Mossoró, a grande importância de atribuir-se a sua "marca”, digamos assim, à produção de sal, petróleo e frutas tropicais do Rio Grande do Norte. Exemplo disso são expressões como: "melão de Mossoró", "sal de Mossoró" e "petróleo de Mossoró". Quando, na verdade, sabemos que a maior parte dessa produção deve-se aos municípios que são polarizados por Mossoró. Neste sentido, Mossoró se beneficia do efeito multiplicador dos investimentos nesses setores, tendo-se em vista sua infra-estrutura urbana propiciar melhores condições para a instalação das empresas que prestam serviços ou vendem produtos necessários à cadeia produtiva do sal, petróleo e fruticultura. Vejamos um pouco do processo de formação e dinamização desses circuitos espaciais da produção.

A economia de Mossoró sempre esteve relacionada à produção do sal, mesmo no século passado já se percebia a relação existente entre as oficinas de carnes secas - as "salgadeiras" - e o sal depositado de forma natural pelas marés, nos baixos e depressões da várzea terminal do Rio Mossoró. Na década de 1970, a modernização chega ao parque salineiro do Rio Grande do Norte com a penetração das empresas multinacionais nas salinas de Mossoró e Areia Branca e, mais acentuadamente, no parque salineiro de Macau.

Essas empresas estrangeiras já chegavam com tecnologia avançada, representadas pela mecanização de todas as bases do processo produtivo das salinas, que se refletia pelo aumento substancial da produtividade, eliminando as possibilidades das pequenas e médias salinas de capital local e regional competir em pé de igualdade com o poderoso capital estrangeiro. Muitas dessas pequenas e médias salinas foram anexadas pelos grandes grupos salineiros, o que concentrou ainda mais a produção de sal nas mãos do grande capital nacional e estrangeiro.

No ano de 1979, foi iniciada a exploração de petróleo e gás na parte terrestre da Bacia Potiguar. A presença da empresa Petróleo Brasileiro S.A. - PETROBRAS no Rio Grande do Norte significou uma articulação entre a realidade do semi-árido nordestino e uma moderna estrutura de produção de energia, que atende às necessidades gestadas noutros centros. Assim, enquanto importante núcleo produtor de petróleo, Mossoró reforçou a sua posição de segunda mais influente cidade potiguar. Neste contexto, o estado do Rio Grande do Norte passou a ocupar o lugar de maior produtor de petróleo em terra no Brasil, e segundo maior produtor em geral, precedido apenas pelo Rio de Janeiro com a Bacia de Campos.

Com a implantação da indústria do petróleo em Mossoró, houve uma crescente demanda pela construção de obras de infra-estrutura e a necessidade de serviços básicos de apoio. Dessa forma, empresas de portes e atividades variadas foram atraídas para Mossoró com vistas a fornecer bens e serviços terceirizados à economia petrolífera. A incorporação dessas unidades ao aparelho produtivo local vem contribuindo para acentuar o predomínio do setor terciário na estrutura econômica de Mossoró. Assim, a exploração petrolífera carreou para a região um volume de investimentos sem precedentes, sendo responsável pela indução de uma nova dinâmica na economia de Mossoró, bem como atração de importantes fluxos migratórios.

A partir da década de 1980 ocorre a consolidação dos pólos dinâmicos de agricultura irrigada no Nordeste, dos quais o pólo Açu/Mossoró ${ }^{3}$ é atualmente reconhecido como uma das áreas de modernização intensa da região Nordeste, ocupando posição de destaque no mercado exportador de frutas tropicais para os Estados Unidos, Comunidade Econômica Européia e países do MERCOSUL. O Rio Grande do Norte é o maior produtor de melão do Brasil.

A instalação dos perímetros irrigados e de grandes agroindústrias na região de influência de Mossoró atraiu novos atores migrantes: trabalhadores rurais, empresários, comerciantes, estudantes, profissionais especializados etc., de várias outras partes do Rio Grande do Norte, e até mesmo dos estados vizinhos como Ceará e Paraíba, para trabalharem com fruticultura. 
Teve importante papel histórico a Mossoró Agroindústria S/A (MAISA), que criada na década de 1960, esteve por mais de 25 anos à frente da atividade frutícola no Rio Grande do Norte, encerrando suas atividades em 2001, e alcançou projeção nacional e internacional na produção e beneficiamento de frutas. Após o fechamento dessa empresa, outras empresas nacionais e internacionais surgiram tanto na região mossoroense, quanto em áreas vizinhas, como a Nolem, a Agrícola Famosa/Intermelon, a Potyfrutas, a Delmonte dentre outras.

Na medida em que ocorreram as sucessivas transformações na base produtiva de Mossoró, principalmente a partir da difusão dos circuitos espaciais da produção do sal, petróleo e fruticulturas, Mossoró intensificou seu papel de pólo de atração e concentração populacional com característica marcante de uma diversificação tanto de serviços, quanto de produção de insumos, concentrando também maior fluxo monetário.

No decorrer de todas as fases de sua formação econômica, portanto, atesta-se o seu domínio na região co mo centro prestador de serviços, seja como pólo agro-industrial, produtor de sal, produtor de petróleo ou produtor de frutas tropicais para exportação, sendo sempre considerável a atração que essa cidade exerce sobre seus vizinhos. (RÊGO, 2002, p. 51).

De acordo com dados do Instituto Brasileiro de Geografia e Estatística (IBGE), Mossoró contava já no ano 2000 com 213.841 habitantes, sendo que 90\% (199.081 habitantes) desta população era urbana. Já na mais atual Contagem de População do IBGE para 2007, a sua população residente aumentou para 234.390 pessoas.

No geral, as atividades de indústria, comércio e serviços do Oeste Potiguar se encontram também concentradas em Mossoró. Conforme os dados da Relação Anual de Indicadores Sociais (RAIS) do Ministério do Trabalho e Emprego (MTE), Mossoró contava em 2005 com 402 indústrias, 1.543 comércios e 865 estabelecimentos prestadores de serviços. Chama-nos atenção, em especial, o aumento demonstrado pelo terciário, por exemplo, na expansão do comércio em 77\% (do número de estabelecimentos nos vinte anos observados, de 1985 a 2005), embora tenha havido uma queda entre 1995 e 2005, e do setor de serviços em 76\%. Ainda segundo a RAIS, para o ano de 2006, Mossoró contava com 411 indústrias, 1.643 comércios e 964 estabelecimentos prestadores de serviços.

Com a modernização e ampliação desses circuitos produtivos, Mossoró vem ampliando a sua função de atendimento a uma crescente e diversificada demanda de produtos e serviços do próprio município, de municípios vizinhos e de outros estados. Isto ocorre à medida que se acentua a necessidade do consumo produtivo (máquinas, equipamentos, serviços de crédito, de consultoria, de assistência técnica, de qualificação profissional, de informação e transportes voltados para a produção), no circuito produtivo do sal, petróleo e fruticultura, e do consumo consuntivo promovido pelas novas rendas que circulam na cidade.

À medida que foi tendo seus papéis ampliados, houve uma ampliação, em contrapartida, da sua área de influência ${ }^{4}$, bem como das relações com outras áreas de influência no Rio Grande do Norte. Essa polarização regional é muito significativa para Mossoró, se levarmos em consideração que na região Nordeste, as capitais tradicionalmente concentram a oferta de equipamentos e serviços e são poucas as opções de centros de nível intermediário. Deve ser notado que estes, apesar de poucos, são tradicionais, e exercem forte polarização em suas áreas, a exemplo de Campina Grande na Paraíba; Petrolina e Juazeiro na Bahia; Juazeiro do Norte, Crato e Barbalha no Ceará e Mossoró no Rio Grande do Norte (REGIC- Regiões de Influência das Cidades - 2007/ IBGE).

As condições locais de infra-estrutura, recursos humanos, fiscalidade, organização sindical, força reivindicatória afastam ou atraem atividades em um dado momento. Muitos municípios sertanejos do Rio Grande do Norte tiveram pouca expansão em sua economia urbana, isto 
tem muita relação com o fato desses estarem próximos de cidades como Mossoró, Natal e Fortaleza, as quais tendem a inibir um maior dinamismo urbano nesses municípios, uma vez que, concentram muitas atividades terciárias e industriais. No caso da fruticultura, por exemplo, para Gomes (1997, p.7):

Os pequenos municípios rurais que concentram a produção irrigada nos Pólos, como Baraúna, Açu, Ipanguaçu e Carnaubais, têm usufruído minimamente da expansão desse tipo de economia da irrigação, reduzindo-se os benefícios a uma tênue diversificação comercial (pequeno comércio, mercadinho, restaurante self-service, lojas de vestuário, etc.) e a algumas instalações de packing house.

Enquanto alguns lugares no Nordeste foram adequados técnica e politicamente para o capital corporativo, e submetidos a uma racionalidade privada obtida com recursos públicos, outros ainda são organizados por elites políticas locais e empresas menos poderosas. Os primeiros seriam do ponto de vista da produtividade, da competitividade, espaços luminosos (SANTOS; SILVEIRA, 2003), enquanto os demais chamar-se-íam espaços opacos (SANTOS; SILVEIRA, ibid.). Mossoró parece se enquadrar nesse primeiro tipo de espaço, por apresentar muitas "pistas" para descobrirmos neste lugar uma intensa modernidade no semi-árido nordestino com uma organização espacial urbana direcionada a permitir e facilitar a realização do capital.

\section{CONSIDERAÇÕES FINAIS}

Para compreender a dinâmica de produção e organização do espaço urbano das cidades nordestinas é preciso contextualizá-las no processo maior das superposições históricas da divisão territorial do trabalho nesta região, e ainda fazer referência as escalas nacional e global. Só assim será possível entender a política territorial de desconcentração espacial das indústrias e centralização (do comando e das ordens) que foi responsável pela valorização recente de alguns lugares, pontos ou manchas no Nordeste que se reorganizaram para atender as demandas reclamadas pelo capital, sob um discurso eficaz do desenvolvimento, da promessa de objetos modernos e empregos vindouros.

O uso competitivo do território beneficia apenas as grandes empresas que dispõem de maiores possibilidades para utilização dos lugares mais aptos à sua instalação, ou para a transformação dos antes inaptos em lugares de eleição global pelo capital. Na guerra dos lugares (SANTOS; SILVEIRA, 2003), a busca competitiva por lugares "produtivos", exclui (mesmo que parcialmente, e em momentos certos), alguns lugares considerados menos produtivos, da lógica territorial de alguns capitais e de políticas públicas. Uma acirrada competição estabelece-se entre lugares, empresas e Estado pela instalação de novos capitais e, mesmo, pela transferência dos já existentes. É de fato uma guerra fiscal (SANTOS; SILVEIRA, ibid.) entre lugares.

A estrutura urbana do Rio Grande do Norte reflete o tratamento que os programas e políticas públicas têm determinado para o estado, em função de interesses corporativos dos atores econômicos hegemônicos, onde algumas cidades são privilegiadas pelos investimentos em detrimento de outras que ainda estão reservados para, talvez, um uso futuro pelo capital. Com essa realidade, percebe-se uma maior concentração de populações e capitais nas duas maiores cidades: Natal e Mossoró, e um aprofundamento da fragilidade nos outros centros urbanos do estado, que são dependentes políticos, econômicos e de prestação de serviços desses dois centros maiores do Rio Grande do Norte.

Esse processo desigual, embora com uma combinação própria, de expansão territorial do capital não é nítido apenas na ordem espacial interurbana do Rio Grande do Norte, o espaço urbano de Mossoró, para citar o nosso objeto de análise, também materializa esses reflexos internamente. O fato de Mossoró concentrar as principais atividades econômicas, culturais, de lazer e também os investimentos no setor púbico - saúde, educação, infra-estrutura - fez com que se conformasse em centro regional de atração de milhares de pessoas que não encontrando o "eldorado" soma-se ao contingente de habitantes da cidade, que sofrem com problemas de falta de moradia, insuficiência 
de serviços básicos, falta de emprego e outros.

É evidente que a inserção de Mossoró na lógica empreendedora capitalista não vem se traduzindo necessariamente em um benefício direto para sua população. Nesse lugar os investimentos vêm sendo dirigidos às áreas e atores econômicos, na maioria, já dotados de condições favoráveis a atender as necessidades demandadas. Podemos tornar esse processo mais claro com a afirmação de Arroyo (2006, p. 83) quando diz que "numerosas e diversas situações mostram que a capacidade de gerar um excedente nem sempre implica a possibilidade de sua apropriação e gestão local".

\section{NOTAS}

(1) A denominação de Região Concentrada foi introduzida na literatura geográfica com as pesquisas dirigidas, no Rio de Janeiro, por Milton Santos e Ana Clara Torres Ribeiro (O conceito de Região Concentrada, 1979). Essa região estaria constituída pelos Estados do Rio de Janeiro, Espírito Santo, Minas Gerais, São Paulo, Paraná, Santa Catarina e Rio Grande do Sul" (SANTOS; SILVEIRA, 2003, p.27). A Região Concentrada caracteriza-se pela densidade do sistema de relações que intensifica os fluxos de mercadorias, capitais e informações. O seu núcleo é a metrópole paulista, que desempenha funções de cidade global e reforça o comando sobre o território nacional.

(2) Posteriormente o IFOCS foi transformado em Departamento Nacional de Obras Contra as Secas (DNOCS).

(3) Fazem parte do Pólo Açu/Mossoró os seguintes municípios: Baraúna, Mossoró, Serra do Mel, Carnaubais, Pendências, Alto Rodrigues, Afonso Bezerra, Ipanguaçu, Itajá, Açu, Upanema. Mossoró é a sede do Pólo Açu/Mossoró.

(4) De acordo com o estudo "Regiões de Influência das Cidades - 2007" do IBGE, para este levantamento Mossoró apresentou como sua área de influência a composição dos Centros Locais de Areia Branca, Augusto Severo, Baraúna, Caraúbas, Felipe Guerra, Frutuoso Gomes, Governador Dix-Sept Rosado, Grossos, Itaú, Janduís, Martins, Messias Targino, Olhod'água do Borges, Tibau, Serra do Mel, Upanema; os Centros de Zona B: Apodi, Patu e Umarizal; e o Centro Sub Regional B de Açu. Para identificar as áreas de influencia, esse estudo levou em consideração as seguintes variáveis: distribuição de bens (produtos industriais) e de serviços (serviços ligados ao capital; administração e direção; educação; saúde; divulgação) de forma complementar (REGIC/IBGE, 2007).

\section{REFERÊNCIA BIBLIOGRÁFICA}

ARAÚJO, Tânia Bacelar de. Herança de diferenciação e futuro de fragmentação. Revista Estudos Avançados do IEA/USP, vol. 2, no. 29, p. 7-36, 1997. Disponível em: <http://www.scielo.br/scielo.php?script=sci_ar ttext\&pid=S0103-40141997000100002>. Acesso em: 22 out. 2007.

ARROYO, Mônica. Dinâmica territorial, circulação e cidades médias. In: SPOSITO, Maria Encarnação Beltrão; SOBARZO, Oscar (Orgs.). Cidades Médias: produção do espaço urbano e regional. São Paulo: Expressão Popular, 2006.

CASTRO, Iná Elias de. O Nordeste como tema de suas elites. In: O Mito da Necessidade. Rio de Janeiro: Bertrand Brasil, 1992.

ELIAS, Denise; PEQUENO, Renato (Orgs.). Difusão do agronegócio e novas dinâmicas socioespaciais. Fortaleza: BNB, 2006.

FELIPE, José Lacerda Alves. Organização do espaço urbano de Mossoró. Fundação Guimarães Duque, Coleção Mossoroense, série c - volume ccxxxvi, 1982.

FELIPE, José Lacerda Alves. Elementos de Geografia do Rio Grande do Norte. Natal: Editora Universitária, 1988.

GOMES, Aldenôr. O pólo fruticultor Açu/Mossoró (RN). Instituto de Pesquisas Sociais - INPSO, da FJN, 1997. Disponível em: <http://www.fundaj.gov.br/observanordeste/obte020.html>. Acesso em 27 nov. 2007.

HARVEY, David. Condição Pós-Moderna: uma pesquisa sobre as origens da mudança cultural. $6^{\mathrm{a}}$ ed. São Paulo: Loyola, 2003.

MOREIRA, Ruy. Geografia: teoria e crítica. Petrópolis: Vozes, 1982.

OLIVEIRA, Francisco de. Elegia para uma Re(li)gião: SUDENE, Nordeste. Planejamento e conflitos de classes. $3^{\text {a }}$ ed. Rio de Janeiro: Paz e Terra, 1981.

RÊGO, Valdecina Anunciata da Silveira. Terceirização e metamorfoses no mundo do trabalho: desafios

Mercator - volume 8, número 17, 2009: set./dez. 
à sustentabilidade social. 2002. 115f. Dissertação (Mestrado em Desenvolvimento e Meio Ambiente) - Universidade do Estado do Rio Grande do Norte, Mossoró, 2002.

ROCHA, Aristotelina Pereira Barreto. Expansão Urbana de Mossoró (período de 1980 a 2004). Natal: Coleção Mossoroense, 2005.

SANTOS, Milton. Por uma economia política da cidade. São Paulo: Hucitec, 1994.

SANTOS, Milton.Técnica, Espaço, Tempo: globalização e meio técnico-científico informacional. $2^{\mathrm{a}}$. ed. São Paulo: Hucitec, 1996.

SANTOS, Milton. A Urbanização brasileira. 5. ed. São Paulo: EDUSP, 2005.

SANTOS, Milton; SILVEIRA, Maria Laura. O Brasil: território e sociedade no início do século XXI. $5^{\circ}$ ed. Rio de Janeiro: Record, 2003.

SOJA, Edward William. Geografia pós-moderna: a reafirmação do espaço na teoria social crítica. Rio de Janeiro: Jorge Zahar Editora, 1993.

SPOSITO, Maria Encarnação Beltrão. Capitalismo e Urbanização. São Paulo: Contexto, 2001.

SPOSITO, Maria Encarnação Beltrão. O desafio metodológico da abordagem interescalar no estudo das cidades médias no mundo contemporâneo. Cidades, Presidente Prudente, v. 3, p. 143-157, 2006.

Trabalho enviado em setembro de 2009

Trabalho aceito em dezembro de 2009 